\title{
Analysis of Household Consumption Behavior and Indebted Self-Selection Effects: Case Study of Thailand
}

\author{
Jianxu Liu $\left(\mathbb{D},{ }^{1}\right.$ Duangthip Sirikanchanarak $\left(\mathbb{D},{ }^{1}\right.$ Songsak Sriboonchitta, ${ }^{1}$ and Jiachun $\mathrm{Xie}^{2}$ \\ ${ }^{1}$ Faculty of Economics, Chiang Mai University, Chiang Mai, Thailand \\ ${ }^{2}$ School of Statistics and Mathematics, Yunnan University of Finance and Economics, Kunming, China \\ Correspondence should be addressed to Jianxu Liu; liujianxu1984@163.com
}

Received 3 September 2017; Accepted 12 March 2018; Published 17 April 2018

Academic Editor: David Bigaud

Copyright (c) 2018 Jianxu Liu et al. This is an open access article distributed under the Creative Commons Attribution License, which permits unrestricted use, distribution, and reproduction in any medium, provided the original work is properly cited.

\begin{abstract}
Copula is deemed to be a good approach for relaxing bivariate or multivariate distributions in econometric models. This paper combines static and dynamic copula functions with endogenous switching to study self-selection effects and interdependence between error terms. This technique, copula-based models, is applied to analyze household consumption behavior and indebted self-selection effects in Thailand. The independent, Gaussian, Frank, Clayton, Gumbel, and Joe copula functions and the relatively rotated copula functions were employed in the empirical work. The best model was selected by the information criterion, AIC. We separated the households into four groups, indebted households, debt-free households, households with housing/land loans, and households without housing/land loans, which favors the examination of the treatment effects of indebted households or households with housing debts. The main results indicate that dynamic copula-based models offer better performance than others, such as classical endogenous switching models or all static copula-based models. Also, the I-I and the G-G models underestimate the treatment effects relative to the best models. Additionally, importantly, the traditional normal bivariate distribution or the static copula function could characterize the relationship as regards errors between household debt choice and household consumption and can lead to very misleading implications about the treatment effects.
\end{abstract}

\section{Introduction}

With rapid economic development and urbanization, household consumption plays an important role in the economic growth of a nation. Household consumption contributes toward dampening private consumption and, thus, aggregate demand and economic activity. Thailand's economic growth has been mainly driven by household consumption. From Figure 1, we can see that household consumption expenditure accounts for $58 \%$ of Thailand's GDP (gross domestic product) in terms of final demand and that the same tends to increase after 2008. Likewise, we can see that the growth of GDP and the household consumption expenditure seem to move with each other closely, which is shown in Figure 2. This is because there have been several government policies oriented to improve economy by boosting household spending, such as rice-farming subsidies, business development loans in rural areas, and tax breaks on new car purchases, and all of them have been used after widespread flooding which devastated the country's economy in 2011. Therefore, this can be taken to imply that household consumption will become a key driving force in Thailand's economy. Obviously, boosting household consumption is an effective measure to retain economic growth. In 2015, the Thai government launched multiple stimulus measures focusing on the rural population and small and medium-sized enterprises (SMEs). For rural population, the first measure involves giving out no and low interest loans worth a total of THB59 billion. For SMEs, the stimulus measure includes low interest loans worth THB100 billion, credit guarantee of THB100 billion, tax exemptions, and tax cuts, as well as a venture capital fund worth THB6 billion. The purpose of the above-mentioned measures is to create shortterm consumption in the form of pushing up household debt, thereby boosting the economic growth. Moreover, household debt could not only help people smoothen their consumption over their lifetimes but also help households build up their 


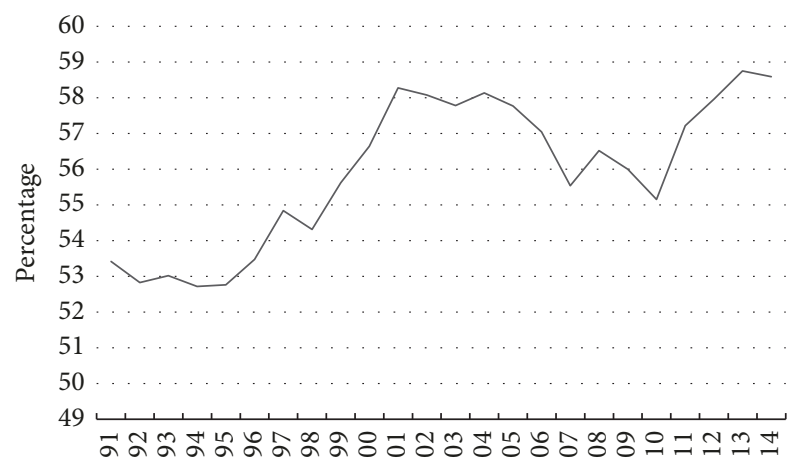

FIGURE 1: Ratio of household consumption expenditure and gross domestic product. Source. Office of the National Economic and Social Development Board.

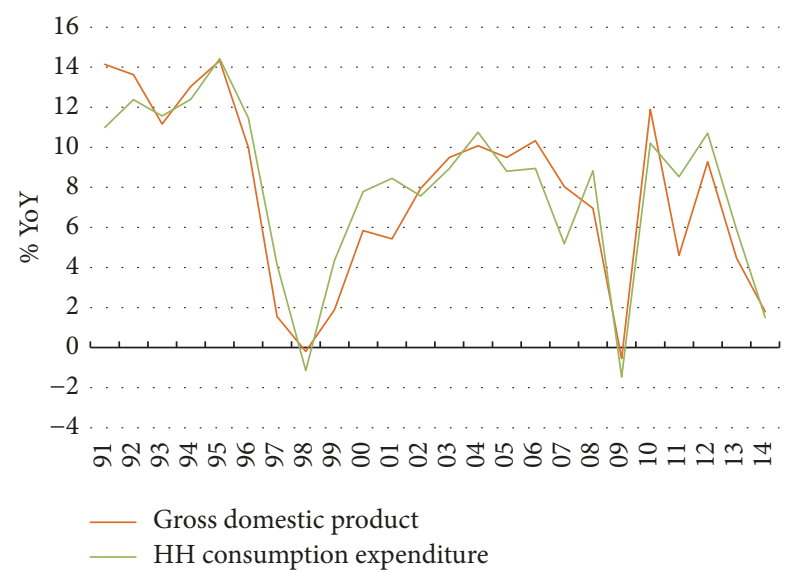

FIGURE 2: Gross domestic product and household consumption expenditure of Thailand. Source. Office of the National Economic and Social Development Board.

physical assets such as land and house. As a result, it is worth considering how household debts quantitatively affect consumption.

In recent years, there have been many studies that have investigated the effects of household debt on household consumption expenditure. For example, Ogawa and Wan [1] examined the effects of household debt on consumption by estimating the consumption functions of total expenditures and of individual expenditure classified by type using Ordinary Least Square (OLS) regression. Some empirical studies suggested that the ratio of the debt associated with land and housing purchases to the market value of tangible asset had significantly negative effects on expenditure after the bubble burst. Moreover, they found that the debt-asset ratio had negative effects on expenditures on semidurable and nondurable goods. Ekici and Dunn [2] investigated the relationship between credit card debt and consumption using Tobit model for the US. Meniago et al. [3] used the Vector Error Correction Model (VECM) to estimate the relationship between household debt and other macroeconomic variables. He found the existence of a long-run cointegrating relationship between household debt and other macroeconomic determinants. Increase in household debt is affected by positive changes in consumer price index, gross domestic product, and household consumption, and household prices and household saving were found to positively contribute to a rise in household debt. Ni and Seol [4] examined how nondurable consumption expenditures in households headed by government employees respond to predictable income changes. They found that moderately excess sensitivity in consumption can be attributed to about nine percent of the households. Kukk [5] used the OLS regression to investigate the estimations and showed that indebtedness measured by the debtto-income ratio hampers consumption as a whole during the recession rather than during the precrisis and the postcrisis periods in a new EU member country. Moreover, the findings suggest that household indebtedness is amplifying the recession, and the debt repayment burden indicates the mechanism. Baker [6] studied the consumption response to household income shocks. They found that highly indebted households are more sensitive to these income fluctuations and that a one standard deviation increase in debt-to-asset ratios increases the elasticity of consumption by approximately $25 \%$.

In general, an indebted household is one with specific assets, much higher household income, high education levels, large household expenditure, and so forth. On the other hand, a debt-free household is one with low assets, no fixed household income, less household expenditure, and so forth. Assume that the indebted household consumption is much higher than the debt-free household consumption. Then, the difference in the consumption between the debt-free household and the indebted household is attributed to households self-selecting themselves into loans based on consumption desires. We argue in all articles that household consumption should not be viewed in isolation from household debt choice. The statistical models ignoring this type of selectivity can induce statistical biases into model estimates. Also, it will indirectly have an effect on the provision of information and policy advice.

To address this drawback, a copula-based endogenous switching model is applied for investigating the effects of household debt on household consumption expenditure and measuring the treatment effect of household debt. Copulabased endogenous switching models allow for better flexibility in joint distributions than the bivariate normal distribution. Also, many copula functions are used for providing a more general dependence structure, as opposed to treating it as a simple linear correlation. This implies that copula-based models can better fit the data than standard endogenous switching models. Smith [7] firstly proposed a copula-based endogenous switching model which was applied to child labor. Thereafter, this model has been widely employed in many empirical analyses. For example, Bhat and Eluru [8] applied the copula-based approach to accommodate residential self-selection effects in travel behavior modeling. Eberth and Smith [9] modeled the participation decision and duration of sporting activity in Scotland. Wichian and Sriboonchitta [10] used it to analyze private and public wage determination for older workers in Thailand.

The contribution of this paper can be listed as follows: first, we propose dynamic copula-based endogenous 
switching models to measure the dynamic dependence structure between household debt and household consumption in Thailand. Dynamic copula-based endogenous switching models can be used to measure the possibly asymmetric and tail dependence between household debt and household consumption. At the same time, dynamic copula-based models can further explain the dependence structure between household debt and household consumption, which is better than the capability of the static copula-based model that was proposed by [7]. Second, this paper is the first study that considers a nonrandom selection of household debt for household consumption behavior. It favors the distinguishing of the differences between debt-free household consumption and indebted household consumption.

The remainder of this paper is organized as follows: In the next section, we introduce the endogenous switching model and the copula functions. In Section 3, we construct the copula-based endogenous switching model. Section 4 describes the data and the variables. In Section 5, we report the empirical results. Section 6 gives us some conclusions.

\section{Background}

As previously mentioned, the endogenous switching model and copulas are the two building blocks of the copulabased model. Therefore, we firstly summarize the endogenous switching model in Section 2.1, and then review the copulas in Section 2.2.

2.1. Endogenous Switching Model. By following Bhat and Eluru [8], the endogenous switching model by two regimes can be expressed as

$$
\begin{aligned}
& y_{i}^{*}=\beta^{\prime} Z_{i}+\varepsilon_{i}, \quad y_{i}=0 \text { if } y_{i}^{*} \leq 0, y_{i}=1 \text { if } y_{i}^{*}>0, \\
& r_{0 i}=\alpha^{\prime} X_{0 i}+\eta_{i}, \quad \text { if } y_{i}=0, \\
& r_{1 i}=\gamma^{\prime} X_{1 i}+\xi_{i}, \quad \text { if } y_{i}=1,
\end{aligned}
$$

where the first two equations represent binary choice model and $y_{i}^{*}$ represents a latent variable, such as $y_{i}=0$ or 1 , implying that a worker is a public or a private sector employee. $r_{0 i}$ and $r_{1 i}, i=1,2, \ldots, N$, denote the dependent variable to be explained in each of the two regimes. $X_{0 i}$ and $X_{1 i}$ represent the independent variables corresponding to each regime. $\beta, \alpha$, and $\gamma$ are the parameter vectors. $\varepsilon_{i}$ is the error term of the binary choice model, and $\eta_{i}$ and $\xi_{i}$ are the error terms of the two regimes, respectively. In general, the standard endogenous switching model assumes that there exists a potential linear correlation between the pairs of error terms: $\varepsilon_{i}$ and $\eta_{i}, \varepsilon_{i}$ and $\xi_{i}$, and that both the pairs are bivariate normal distributions, and a full information maximum likelihood method is used to estimate the endogenous switching model. In addition, there are also some researchers and academicians who extended this model by using nonnormal bivariate distributions, two-step estimation methods, and so forth (see [8]).

In endogenous switching models, measurement of the treatment effect is very interesting. A "treatment effect" is the average causal effect of a binary $(0-1)$ variable on an outcome variable of scientific or policy interest. The term "treatment effect" originated in medical literature concerned with the causal effects of binary, yes-or-no "treatments," such as an experimental drug or a new surgical procedure. Average treatment effect (ATE) and average treatment effect on the treated (ATT) are two common methods of measure for causal effects [11]. ATE and ATT can be expressed as

$$
\begin{aligned}
\mathrm{ATE} & =E\left[r_{1}-r_{0}\right]=E(r \mid y=1)-E(r \mid y=0), \\
\mathrm{ATE} & =\frac{1}{N} \sum_{i=1}^{N}\left(\widehat{r}_{1, i}-\widehat{r}_{0, i}\right), \\
\mathrm{ATT} & =E\left[r_{1}-r_{0} \mid y=1\right] \\
& =E\left(r_{1} \mid y=1\right)-E\left(r_{0} \mid y=1\right), \\
\mathrm{ATT} & =\frac{1}{N_{1}} \sum_{i=1}^{N_{1}}\left(\widehat{r}_{1, i}-\widehat{r}_{0, i}\right),
\end{aligned}
$$

where ATE and A $\widehat{\mathrm{TT}}$ are the estimated ATE and ATT, respectively. ATE means the difference between the average outcome $(r)$ for observations that receive treatment and the average outcome for observations that receive control.

2.2. Copulas. Copulas are popular in high-dimensional statistical applications as they allow one to easily model and estimate the distribution of random vectors by estimating margins and dependence separately. There are many parametric copula families available, which usually have parameters that control the strength of dependence. In this study, we focus on the presentation of the bivariate copula, which will be used later. Given a joint distribution $H$ of two random variables $X$ and $Y$, the function $C(\cdot, \cdot)$ can be defined on $[0,1]^{2}$ by the following equation:

$$
C(F(x), G(y))=H(x, y)
$$

is a copula, where $F$ and $G$ are marginal distributions of $X$ and $Y$, respectively. $C(\cdot, \cdot)$ satisfies the following properties:

(1) $C(u, 0)=C(0, v)$ for all $u$ and $v$ in $[0,1]$;

(2) $C(u, 1)=u$ and $C(1, v)=v$ for all $u$ and $v$ in $[0,1]$;

(3) For all $0 \leq u_{1} \leq u_{2} \leq 1$ and $0 \leq v_{1} \leq v_{2} \leq 1$,

$$
C\left(u_{2}, v_{2}\right)-C\left(u_{2}, v_{1}\right)-C\left(u_{1}, v_{2}\right)+C\left(u_{1}, v_{1}\right) \geq 0 \text {. }
$$

Fréchet-Hoeffding bounds for copula functions are crucial to select an appropriate copula that covers the sample space between the lower and the upper bounds and that as a parameter of copula approaches the lower (upper) bound of its permissible range. The Fréchet-Hoeffding bounds for copula functions can be expressed as

$$
\begin{aligned}
W(u, v) & =\max (u+v-1,0) \leq C(u, v) \leq \min (u, v) \\
& =M(u, v)
\end{aligned}
$$

where $W$ is the Fréchet-Hoeffding lower bound and $M$ is the Fréchet-Hoeffding upper bound (see $[12,13])$. 

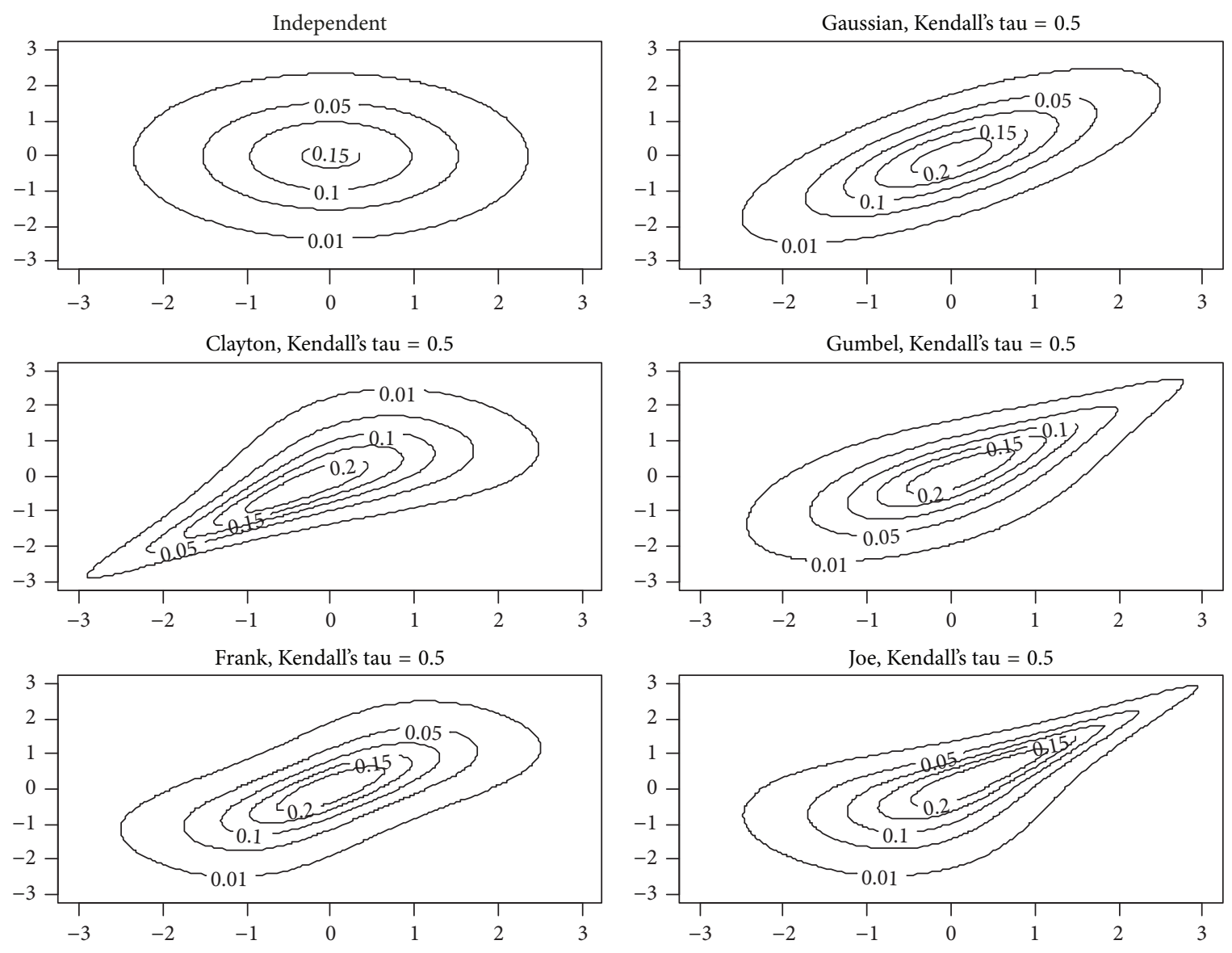

Figure 3: The contour plot of copula functions with normal marginal distribution.

If the random vector $(X, Y)$ has a joint density $h(x, y)$, it can be expressed as a function of the copula density by

$$
\begin{aligned}
h(x, y) & =\frac{\partial^{2} H(x, y)}{\partial x \partial y}=\frac{\partial^{2} C(u, v)}{\partial u \partial v} \frac{\partial F(x)}{\partial x} \frac{\partial G(y)}{\partial y} \\
& =c(u, v) f(x) g(y),
\end{aligned}
$$

where $f(x)$ and $g(y)$ are the marginal densities, $u=F(x)$, and $v=G(y)$. The small letter $c$ represents the density function of the copula.

The different copula functions have different characteristics. For example, Gaussian copula cannot capture tail dependence; Clayton copula can capture lower tail dependence, while Gumbel copula is used to measure upper tail dependence of random variables. Figure 3 demonstrates several copula contour plots under standard normal distribution. The contour plots are generated based on the value of Kendall's tau equaling 0.5. These plots show the evidence that different copula functions have different characteristics in terms of tail dependence, and it is necessary that this study employs the copula model to provide a flexible method of constructing multivariate distributions, given the marginal distributions and the dependence structures separately. However, these copulas can only capture positive dependence except the Gaussian and the Frank copulas. Fortunately, these copulas may then be "rotated" and applied again. A thorough review of rotated copulas may be found in $[14,15]$. There are three rotated forms: rotated 90 degrees, rotated 180 degrees, and rotated 270 degrees. When rotating the copulas by 180 degrees, one obtains the corresponding survival copulas. Nonrotated Clayton copula can capture lower tail dependence, while survival Clayton copula can measure upper tail dependence. Also, rotation by 90 degrees and 270 degrees allows for the modeling of negative dependence. The distribution functions of copulas rotated by 90 degrees, 180 degrees, and 270 degrees are given as follows:

$$
\begin{aligned}
C_{90}(u, v) & =v-C(1-u, v), \\
C_{180}(u, v) & =u+v-1+C(1-u, 1-v), \\
C_{270}(u, v) & =u-C(u, 1-v) .
\end{aligned}
$$

The copula approaches the Fréchet-Hoeffding lower (upper) bound. Therefore, we can make use of some copula families that cover a large dependence as much as possible, such as the (rotated) Clayton, the (rotated) Gumbel, and the (rotated) Joe copula families, which can represent both negative and positive dependence. 


\section{Copula-Based Endogenous Switching Model}

The classical endogenous switching model assumes that the two pairs of error terms have bivariate normal distribution. Smith [7] proposed to relax this assumption and to model the dependence between $\left(\varepsilon_{i}, \eta_{i}\right)$ and $\left(\varepsilon_{i}, \xi_{i}\right)$ by using Archimedean copulas. In this study, we use many copula families to construct a copula-based endogenous switching model and select the best fit in terms of the Akaike information criterion (AIC). It is different in that we will assume the copula parameter depends on some forcing variables corresponding to some evolution equations. We introduce the full information maximum likelihood approach to estimate the copula-based endogenous switching model in this section.

We assume that the error term $\varepsilon_{i}$ has standard normal distribution, while both $\eta_{i}$ and $\xi_{i}$ have normal distribution, but they have scale parameters $\sigma_{\eta}$ and $\sigma_{\xi}$, respectively. Since the marginals are known, the joint distribution of $\varepsilon_{i}$ and $\eta_{i}$, $H_{0}\left(\varepsilon_{i}, \eta_{i}\right)$, can be constructed by copula $C_{0}\left(F\left(\varepsilon_{i}\right), G_{\eta}\left(\eta_{i}\right) ; \theta_{i}\right)$, where $\theta_{i}$ is the copula parameter for each individual. Similarly, the joint distribution of $\varepsilon_{i}$ and $\xi_{i}, H_{1}\left(\varepsilon_{i}, \xi_{i}\right)$, corresponds to $C_{1}\left(F\left(\varepsilon_{i}\right), G_{\xi}\left(\xi_{i}\right) ; \theta_{i}\right)$. Following [8], the likelihood function of the copula-based endogenous switching model can be written as

$$
\begin{aligned}
L= & \prod_{i=1}^{N}\left[\frac{1}{\sigma_{\eta}} \cdot g_{\eta}\left(\frac{r_{0 i}-\alpha^{\prime} X_{0 i}}{\sigma_{\eta}}\right)\right. \\
& \left.\cdot \frac{\partial}{\partial v_{i}^{0}} C_{0}\left(u_{i}^{0}, v_{i}^{0} ; \theta_{i}^{0}\right)\right]^{1-y_{i}} \times\left[\frac{1}{\sigma_{\xi}} \cdot g_{\xi}\left(\frac{r_{1 i}-\gamma^{\prime} X_{1 i}}{\sigma_{\xi}}\right)\right. \\
& \left.\cdot\left\{1-\frac{\partial}{\partial v_{i}^{1}} C_{1}\left(u_{i}^{1}, v_{i}^{1} ; \theta_{i}^{1}\right)\right\}\right]^{y_{i}},
\end{aligned}
$$

where $u_{i}^{0}=u_{i}^{1}=F\left(-\beta^{\prime} Z_{i}\right), v_{i}^{0}=G_{\eta}\left(\left(r_{0 i}-\alpha^{\prime} X_{0 i}\right) / \sigma_{\eta}\right)$, and $v_{i}^{1}=G_{\xi}\left(\left(r_{1 i}-\gamma^{\prime} X_{1 i}\right) / \sigma_{\xi}\right)$. Different copulas have different characteristics, such as upper tail dependence, lower dependence, positive dependence, and negative dependence. Therefore, it is an excellent choice that we apply more copula families and relevant rotated copulas that can potentially capture the appropriate dependence between two random variables. In this study, we systematically consider several copula families including the Gaussian, Frank, Clayton, Gumbel, and Joe families as well as their relevant rotated versions. The model with the best fit-complexity trade-off is selected using the AIC criterion [16]. Other popular copula families, such as the Farlie-Gumbel-Morgenstern (FGM) copula and the Ali-Mikhail-Haq (AMH) copula, have been discarded because they cannot achieve Fréchet bounds and can only accommodate relatively weak dependence between the margins. The ranges of dependence of Kendall's tau and Spearman's rho for the FGM copula are $[-2 / 9,2 / 9]$ and $[-1 / 3,1 / 3]$, respectively; the Kendall's tau of the AMH copula is bounded to the interval $[-0.1817,0.3333]$, and the range of Spearman's rho is $[-0.2711,0.4784]$ (see $[17,18]$ ).

Bhat and Eluru [8] showed that standard endogenous switching models may mislead the implications about the treatment effect by comparing them using copula-based models. However, Smith [7] and Bhat and Eluru [8] did not provide any interpretation for dependence parameters. We consider that the parameters vary according to some evolution equation. We propose the following evolution equations for the Gaussian and the other copulas:

$$
\begin{aligned}
& \rho_{i}^{*}=\delta^{s}+\varphi^{s} V_{i}, \\
& \tau_{i}^{*}=\delta^{s}+\varphi^{s} V_{i},
\end{aligned}
$$

where $s=0$ or 1 denotes the different regimes and $\rho_{i}$ and $\tau_{i}$ represent Pearson's correlation of the Gaussian copula and Kendall's tau of the other copulas. $\rho_{i}^{*}=-\ln \left[\left(1-\rho_{i}\right) /\left(\rho_{i}+1\right)\right]$ and $\tau_{i}^{*}=-\ln \left[\left(1-\tau_{i}\right) /\left(\tau_{i}+1\right)\right]$ are the logistic transformation, which can guarantee the dependence with the interval $(-1,1)$. $V$ is a vector of forcing variables, which can be determined by practical issues. $\delta$ is a constant term, and $\varphi$ is the parameters of the forcing variables.

\section{Data}

The household dataset used in this study is from the Socioeconomic Surveys (SES) in 2013. The sampling was conducted through random proportional sampling, and the dataset contains 21,214 observations. This dataset was gathered by the National Statistical Office workers who visit the sample households every two years.

4.1. Data Descriptive. For the purpose of characterizing the indebted and the debt-free household consumption behavior, we classified all households into four groups: the indebted household, the debt-free household, the household with housing/land loans, and the household without housing/land loans groups. Households that have debts and households that have housing/land debts are expressed by the dummy variables 0 and 1 , respectively. The loans of indebted households consist of business, education, consumption, housing, land, and so forth. Table 1 summarizes the descriptive statistics of the main socioeconomic variables that include monthly consumption per household, monthly income per household, monthly expenditure per household, total asset of the household, age of the head of the household, number of household members, and number of children in the families. First, there are 10,961 households with debt and 10,253 households without debt in our total sample. At the same time, the number of households with housing/land debt is 1,633, which represents 15 percent of all households with debt. The leftover is no housing/land debt, which comprises 19,581 households. Second, the head of the household with debt is younger than the head of the household without debt at any quantile level, and the levels of family size, income, consumption, expenditure, and asset are larger in households with debt than in households without debt at any quantile level, which is consistent with the requirements of household indebtedness. In addition, the consumption, income, expenditure, and assets in households with housing/land debt are about double those of households without housing/land debt at any quantile level as well. Upon comparing the characteristics of households between households with total debt and households with land, we can conclude that households with housing/land debt have higher consumption and income as well as assets and liabilities. 
TABLE 1: Data descriptive of main variables (Baht).

\begin{tabular}{|c|c|c|c|c|c|c|c|c|}
\hline Variable & Consumption & Income & Expenditure & Asset & Age & Family size & Children & Debt \\
\hline \multicolumn{9}{|c|}{ Debt-free sample: 10253 obs. } \\
\hline Min & 1018 & 10 & 1018 & 0 & 13 & 1 & 0.00 & 0 \\
\hline 1st quantile & 7068 & 8300 & 7620 & 112000 & 41 & 1 & 0.00 & 0 \\
\hline Mean & 13958 & 21831 & 15626 & 1277944 & 53.61 & 2.54 & 0.40 & 0 \\
\hline 3rd quantile & 16530 & 23864 & 18504 & 1190000 & 67 & 3 & 1.00 & 0 \\
\hline Max & 333725 & 8820684 & 344325 & 369000000 & 99 & 14 & 8.00 & 0 \\
\hline \multicolumn{9}{|c|}{ Indebtedness: 10961 obs. } \\
\hline Min & 1797 & 37 & 1880 & 0 & 16 & 1 & 0.00 & 200 \\
\hline 1st quantile & 10014 & 12500 & 11329 & 445000 & 42 & 2 & 0.00 & 30000 \\
\hline Mean & 19654 & 30219 & 22715 & 1757039 & 51.03 & 3.39 & 0.72 & 321325 \\
\hline 3rd quantile & 24542 & 35147 & 28446 & 2004000 & 59 & 4 & 1.00 & 350000 \\
\hline Max & 336900 & 2067000 & 359405 & 267000000 & 96 & 15 & 7.00 & 12000000 \\
\hline \multicolumn{9}{|c|}{ Households without housing debt: 19581 obs. } \\
\hline Min & 1018 & 10 & 1018 & 0 & 13 & 1 & 0.00 & 0 \\
\hline 1st quantile & 8204 & 9696 & 9013 & 225000 & 42 & 2 & 0.00 & 0 \\
\hline Mean & 15856 & 24054 & 17901 & 1414177 & 52.54 & 2.96 & 0.56 & 0 \\
\hline 3rd quantile & 19104 & 27308 & 21691 & 1473800 & 63 & 4 & 1.00 & 0 \\
\hline Max & 333725 & 8820684 & 344325 & 369000000 & 99 & 15 & 8.00 & 0 \\
\hline \multicolumn{9}{|c|}{ Households with housing debt: 1633 obs. } \\
\hline Min & 3885 & 345 & 4062 & 0 & 21 & 1 & 0.00 & 1400 \\
\hline 1st quantile & 15925 & 24858 & 18682 & 1003000 & 48 & 2 & 0.00 & 309900 \\
\hline Mean & 29437 & 51488 & 35928 & 2861359 & 49.11 & 3.22 & 0.66 & 1007088 \\
\hline 3rd quantile & 36617 & 60667 & 45498 & 3540000 & 56 & 4 & 1.00 & 1400000 \\
\hline Max & 336900 & 2067000 & 359400 & 205000000 & 92 & 9 & 4.00 & 10000000 \\
\hline
\end{tabular}

4.2. Variables Considered. In this part, we would like to introduce the variables that we used in the estimation. We used the debt decision that takes the value 1 if the household has debt or housing/land debt; otherwise, the value equals 0 . The selection effects of indebtedness are conditional on other observed determinants which are the logarithms of the asset, expenditure, number of children, income, and age of the household head. When we consider the consumption equation, the dependent variable is assumed to be the ratio of consumption expenditure to disposable income so as to avoid the heteroscedasticity problem. As socioeconomic variables determine consumption, we select some variables as independent variables, which include the reciprocal of the household disposal, saving rate, number of members, number of workers, age of the household head, square of the age of the household head divided by 100 , and number of workers with a stable earning job (earned from business, industry, and/or nonfarming business). Moreover, the debt-asset ratio is one of the independent variables for indebted households. Thus, the endogenous switching model in this study can be given by

$$
\begin{aligned}
\operatorname{debt}_{i}^{*}= & \beta_{0}+\beta_{1} \text { ln asset } \\
& +\beta_{2} \text { ln exp enditure } \\
& +\beta_{3} \text { ln children } \\
& +\beta_{4} \text { ln income }_{i} \\
& +\beta_{5} \ln \text { age }_{i}+\varepsilon_{i}, \\
\frac{C_{0 i}}{\mathrm{DI}_{0 i}}= & \alpha_{0}+\alpha_{1} \frac{1}{\mathrm{DI}_{0 i}}+\alpha_{2} \text { savingrate }_{0 i}+\alpha_{3} \text { age }_{0 i}
\end{aligned}
$$

$$
\begin{aligned}
& +\frac{\alpha_{4} \operatorname{age}_{0 i}^{2}}{100}+\alpha_{5} \mathrm{FS}_{0 i}+\alpha_{6} \mathrm{NW}_{0 i} \\
& +\alpha_{7} \mathrm{NSEW}_{0 i}+\eta_{i} \\
\frac{C_{1 i}}{\mathrm{DI}_{1 i}}= & \gamma_{0}+\gamma_{1} \frac{1}{\mathrm{DI}_{1 i}}+\gamma_{2} \text { savingrate }_{1 i}+\gamma_{3} \mathrm{age}_{1 i} \\
& +\frac{\gamma_{4} \mathrm{age}_{1 i}^{2}}{100}+\gamma_{5} \mathrm{FS}_{1 i}+\gamma_{6} \mathrm{NW}_{1 i} \\
& +\gamma_{7} \mathrm{NSEW}_{1 i}+\gamma_{8} \mathrm{DAR}_{1 i}+\xi_{i}
\end{aligned}
$$

where debt* represents the latent variable of household debt or housing/land debt in each dataset; $C_{0}$ and $C_{1}$ are the consumption expenditures of debt-free households and indebted households, respectively; DI is the disposal income; FS is the family size; NW is the number of workers; NSEW is the number of workers with a stable income; and DAR is the debt-asset ratio.

\section{Empirical Results}

In this study, we use six copula functions to model endogenous switching and self-selection effects. This is because of the fact that different copula functions have different characteristics. For example, Gaussian copula cannot capture tail dependence; Clayton copula can capture lower 
TABLE 2: Result of Akaike information criterion (AIC) from copula-based models.

\begin{tabular}{|c|c|c|c|c|c|c|}
\hline & Ind & Gau & Frank & Clayton & Gumbel & Joe \\
\hline \multicolumn{7}{|l|}{ Case 1} \\
\hline Ind & -132169.0 & -132178.1 & -133060.3 & -132117.5 & -132886.7 & -133766.3 \\
\hline Gau & -132168.3 & -132177.5 & -132875.4 & -132648.1 & -132675.1 & -133759.6 \\
\hline Frk & -133259.2 & -133225.6 & -133487.3 & -132782.4 & -133288.4 & -134327.5 \\
\hline Clt & -132412.1 & -132423.2 & -133135.0 & -132378.6 & -133135.0 & -134020.2 \\
\hline Gumb & -132159.8 & -132660.7 & -132854.9 & -132423.1 & -132650.7 & -133356.2 \\
\hline Joe & -132173.5 & -132659.1 & -132853.1 & -132420.0 & -132650.1 & -133343.8 \\
\hline RGumb90 & -132474.0 & -132480.8 & -133645.4 & -132417.4 & -132870.5 & -133990.4 \\
\hline RGumb270 & -132166.0 & -132174.6 & -132788.3 & -131946.3 & -132644.6 & -134069.9 \\
\hline RJoe90 & -133433.3 & -133435.6 & -133961.2 & -132559.4 & -134277.3 & -133983.0 \\
\hline RJoe270 & -132634.1 & -132184.2 & -131624.0 & -129560.0 & -133160.5 & -133034.0 \\
\hline RClt90 & -132621.8 & -132174.4 & -132880.9 & -132467.2 & -132677.2 & -133764.5 \\
\hline RClt270 & -132622.5 & -132176.2 & -132881.6 & -132468.3 & -132677.9 & -133764.5 \\
\hline \multicolumn{7}{|l|}{ Case 2} \\
\hline Ind & -149331.5 & -149334.7 & -149417.6 & -149329.3 & -149644.3 & -149799.3 \\
\hline Gau & -149350.8 & -149351.7 & -149430.4 & -149348.6 & -149656.9 & -149812.1 \\
\hline Frk & -149393.2 & -149388.7 & -149469.6 & -149383.7 & -149691.9 & -149845.8 \\
\hline Clt & -149443.8 & -149445.0 & -149524.6 & -149419.5 & -149746.4 & -149903.0 \\
\hline Gumb & -149336.2 & -149336.6 & -149408.4 & -149290.4 & -149551.6 & -149605.3 \\
\hline Joe & -149335.6 & -149336.5 & -149415.6 & -149289.4 & -149551.7 & -149601.9 \\
\hline RGumb90 & -149336.2 & -149337 & -149415.7 & -149333.4 & -149597.5 & -149719.4 \\
\hline RGumb270 & -149334.4 & -149335.3 & -149406.4 & -149286.4 & -149549.8 & -149598.4 \\
\hline RJoe90 & -149336.3 & -149337.1 & -149559.2 & -149333.6 & -149597.6 & -149930.3 \\
\hline RJoe270 & -149334.4 & -149335.4 & -149410.5 & -149324.8 & -149595.9 & -149598.4 \\
\hline RClt90 & -147276.3 & -149334.8 & -149119.0 & -149231.6 & -149578.2 & -149695.9 \\
\hline RClt270 & -149336.9 & -149475.5 & -149552.2 & -149254.6 & -149579.7 & -149924.2 \\
\hline
\end{tabular}

Source. Computation.

tail dependence, while Gumbel copula is used to measure upper tail dependence of random variables. Therefore, the independent, Gaussian, Clayton, Frank, Gumbel, Joe, rotated Clayton, rotated Gumbel, and rotated Joe copulas are applied to endogenous switching models. The preferred copula-based endogenous switching model is selected based on the AIC. We use the R program to estimate the model, and the starting values are obtained from "glm" and " $\mathrm{lm}$ " functions, and the maxLik package with the BFGS algorithm is applied to maximize the log-likelihood function of the R software.

As mentioned above, we firstly estimate all the alternative models and then select the preferred models based on the AIC. Hereafter, the copula functions among the preferable models are transformed into dynamic copula functions, and then the maximum likelihood method is used to estimate the dynamic copula-based endogenous switching models. Moreover, there are 72 models for each dataset. In the first case, the dataset is divided into two groups: indebted households and debt-free households. In the second case, we separate the dataset into households with and without housing/land debt. The results of the AIC are shown in Table 2. According to the values of AIC, we find that the Joe-Frank copulas-based endogenous switching model offers better performance than the others for the first case. The Joe and the Frank copulas are used to capture the dependence structures between the error pairs $\left(\varepsilon_{i}, \eta_{i}\right)$ and $\left(\varepsilon_{i}, \xi_{i}\right)$, respectively. For the second case, the endogenous switching model based on the rotated-by-90degree Joe copula and the Joe copula is the best one among all the alternative models. Therefore, the dynamic Joe-Frank copulas-based endogenous switching model was applied to the first case, while the endogenous switching model based on the dynamic rotated-by-90-degree Joe copula and Joe copula was used for the second case. It is well known that household income is related to household debt and household consumption. Then, household income may be explained by the relation between the error pairs $\left(\varepsilon_{i}, \eta_{i}\right)$ and $\left(\varepsilon_{i}, \xi_{i}\right)$.

In the following presentation of the empirical results, we focus on the results of the best static copula-based models and the corresponding dynamic copula-based models. All empirical results are presented in Tables 3 and 4. First, the estimation results for the dependence are discussed in Section 5.1. Second, the results of the sample selection equation are shown in Section 5.2. Third, we will discuss the results of the endogenous switching and self-selection effects in Section 5.3. Finally, the treatment effects are reported in Section 5.4.

5.1. Estimation Results for Dependence. We now turn to show the estimation results of the copula-based endogenous switching model. Table 3 shows all the parameter estimates for the two cases. We can see that the parameter estimates 
TABLE 3: Estimation results of copula-based endogenous switching model.

(a) Estimation of sample selection equation

\begin{tabular}{|c|c|c|c|c|}
\hline \multirow{2}{*}{ Parameter } & \multicolumn{2}{|c|}{ Case 1 (all kinds of debt) } & \multicolumn{2}{|c|}{ Case 2 (housing/land debt) } \\
\hline & Frank-Joe & Dynamic Frank-Joe & R-Joe90-Joe & Dynamic R-Joe90-Joe \\
\hline \multirow{2}{*}{ Intercept } & -3.7010 & -3.8470 & -7.0430 & -7.2670 \\
\hline & $(-20.468)^{* * *}$ & $(-9.783)^{* * *}$ & $(-20.489)^{* * *}$ & $(-25.896)^{* * *}$ \\
\hline \multirow{2}{*}{$\ln$ asset } & 0.1543 & 0.1478 & 0.2047 & 0.2056 \\
\hline & $(23.194)^{* * *}$ & $(19.866)^{* * *}$ & $(14.431)^{* * *}$ & $(14.514)^{* * *}$ \\
\hline \multirow{2}{*}{$\ln \exp$} & 0.5055 & 0.5557 & 0.2990 & 0.2938 \\
\hline & $(18.229)^{* * *}$ & $(13.293)^{* * *}$ & $(6.640)^{* * *}$ & $(6.537)^{* * *}$ \\
\hline \multirow{2}{*}{ ln children } & 0.0521 & 0.0502 & 0.0028 & 0.0033 \\
\hline & $(20.057)^{* * *}$ & $(18.87)^{* * *}$ & $(0.725)$ & $(0.834)$ \\
\hline \multirow{2}{*}{ ln income } & -0.1782 & -0.2010 & 0.1975 & 0.2232 \\
\hline & $(-7.740)^{* * *}$ & $(-8.021)^{* * *}$ & $(5.708)^{* * *}$ & $(6.233)^{* * *}$ \\
\hline \multirow{2}{*}{ ln age } & -0.3141 & -0.3196 & -0.5420 & -0.5400 \\
\hline & $(-9.773)^{* * *}$ & $(-5.525)^{* * *}$ & $(-8.8090)^{* * *}$ & $(-8.981)^{* * *}$ \\
\hline
\end{tabular}

(b) Estimation of consumption function for households without debt

\begin{tabular}{|c|c|c|c|c|}
\hline \multirow{2}{*}{ Parameter } & \multicolumn{2}{|c|}{ Case 1 (all kinds of debt) } & \multicolumn{2}{|c|}{ Case 2 (housing/land debt) } \\
\hline & Frank-Joe & Dynamic Frank-Joe & R-Joe90-Joe & Dynamic R-Joe90-Joe \\
\hline \multirow{2}{*}{ Intercept } & 0.9033 & 0.9211 & 0.8981 & 0.8983 \\
\hline & $(248.576)^{* * *}$ & $(276.193)^{* * *}$ & $(279.083)^{* * *}$ & $(279.348)^{* * *}$ \\
\hline \multirow{2}{*}{$\ln$ ad income } & 239.7000 & 203.00 & 299.1000 & 296.1000 \\
\hline & $(1752.608)^{* * *}$ & $(112.866)^{* * *}$ & $(1111.661)^{* * *}$ & $(1798.407)^{* * *}$ \\
\hline \multirow{2}{*}{ ln saving rate } & -0.9526 & -0.9575 & -0.9390 & -0.9387 \\
\hline & $(-894.060)^{* * *}$ & $(-769.568)^{* * *}$ & $(-1321.572)^{* * *}$ & $(-1329.810)^{* * *}$ \\
\hline \multirow{2}{*}{ ln age } & -0.0009 & -0.0009 & -0.0011 & -0.0011 \\
\hline & $(-5.793)^{* * *}$ & $(-7.158)^{* * *}$ & $(-8.761)^{* * *}$ & $(-8.794)^{* * *}$ \\
\hline \multirow{2}{*}{ ln age 2} & 0.0009 & 0.0009 & 0.0012 & 0.0012 \\
\hline & $(6.647)^{* * *}$ & $(7.574)^{* * *}$ & $(9.596)^{* * *}$ & $(9.633)^{* * *}$ \\
\hline \multirow{2}{*}{ ln family size } & 0.0113 & 0.0096 & 0.0139 & 0.0140 \\
\hline & $(28.464)^{* * *}$ & $(27.538)^{* * *}$ & $(46.928)^{* * *}$ & $(47.333)^{* * *}$ \\
\hline \multirow{2}{*}{ ln workers } & -0.0130 & -0.0116 & -0.0131 & -0.0131 \\
\hline & $(-22.412)^{* * *}$ & $(-22.492)^{* * *}$ & $(-29.343)^{* * *}$ & $(-29.293)^{* * *}$ \\
\hline \multirow{2}{*}{ ln good workers } & 0.0092 & 0.0085 & 0.0065 & 0.0065 \\
\hline & $(10.191)^{* * *}$ & $(10.591)^{* * *}$ & $(10.021)^{* * *}$ & $(10.078)^{* * *}$ \\
\hline \multirow{2}{*}{$\sigma_{\eta}$} & 0.0437 & 0.0374 & 0.0459 & 0.0606 \\
\hline & $(128.787)^{* * *}$ & $(108.801)^{* * *}$ & $(196.144)^{* * *}$ & $(67.739)^{* * *}$ \\
\hline
\end{tabular}

(c) Estimation of consumption function for indebted households

\begin{tabular}{|c|c|c|c|c|}
\hline \multirow{2}{*}{ Parameter } & \multicolumn{2}{|c|}{ Case 1 (all kinds of debt) } & \multicolumn{2}{|c|}{ Case 2 (housing/land debt) } \\
\hline & Frank-Joe & Dynamic Frank-Joe & R-Joe90-Joe & Dynamic R-Joe90-Joe \\
\hline \multirow{2}{*}{ Intercept } & 0.8645 & 0.8653 & 0.8405 & 0.8344 \\
\hline & $(156.582)^{* * *}$ & $(163.123)^{* * *}$ & $(40.575)^{* * *}$ & $(41.127)^{* * *}$ \\
\hline \multirow{2}{*}{ In ad income } & 273.300 & 271.100 & 346.03 & 339.6000 \\
\hline & $(984.908)^{* * *}$ & $(102.664)^{* * *}$ & $(196.600)^{* * *}$ & $(519.557)^{* * *}$ \\
\hline \multirow{2}{*}{ ln saving rate } & -0.9380 & -0.9384 & -0.9250 & -0.9179 \\
\hline & $(-897.758)^{* * *}$ & $(-896.498)^{* * *}$ & $(-200.871)^{* * *}$ & $(-197.062)^{* * *}$ \\
\hline \multirow{2}{*}{ ln age } & -0.0013 & -0.0013 & -0.0076 & -0.0073 \\
\hline & $(-5.906)^{* * *}$ & $(-5.994)^{* * *}$ & $(-9.055)^{* * *}$ & $(-9.330)^{* * *}$ \\
\hline \multirow{2}{*}{$\ln$ age 2} & 0.0009 & 0.0009 & -0.0023 & -0.0020 \\
\hline & $(4.558)^{* * *}$ & $(4.622)^{* * *}$ & $(-2.798)^{* *}$ & $(-2.481)^{*}$ \\
\hline \multirow{2}{*}{ ln family size } & 0.0167 & 0.0166 & 0.0018 & 0.0015 \\
\hline & $(40.483)^{* * *}$ & $(40.153)^{* * *}$ & $(13.212)^{* * *}$ & $(2.005)^{*}$ \\
\hline
\end{tabular}


(c) Continued.

\begin{tabular}{|c|c|c|c|c|}
\hline \multirow{2}{*}{ Parameter } & \multicolumn{2}{|c|}{ Case 1 (all kinds of debt) } & \multicolumn{2}{|c|}{ Case 2 (housing/land debt) } \\
\hline & Frank-Joe & Dynamic Frank-Joe & R-Joe90-Joe & Dynamic R-Joe90-Joe \\
\hline \multirow{2}{*}{ ln workers } & -0.0072 & -0.0072 & 0.0208 & 0.0171 \\
\hline & $(-11.611)^{* * *}$ & $(-11.547)^{* * *}$ & $(14.990)^{* * *}$ & $(13.230)^{* * *}$ \\
\hline \multirow{2}{*}{ ln good workers } & 0.0056 & 0.0056 & -0.0086 & -0.0090 \\
\hline & $(6.981)^{* * *}$ & $(6.961)^{* * *}$ & $(-4.244)^{* * *}$ & $(-4.521)^{* * *}$ \\
\hline \multirow{2}{*}{ ln debt ratio } & -0.0001 & -0.0001 & 0.0139 & 0.0139 \\
\hline & $(-24.850)^{* * *}$ & $(-23.894)^{* * *}$ & $(5.592)^{* * *}$ & $(5.680)^{* * *}$ \\
\hline \multirow{2}{*}{$\sigma_{\xi}$} & 0.0504 & 0.0474 & 0.0569 & 0.0549 \\
\hline & $(154.600)^{* * *}$ & $(148.663)^{* * *}$ & $(70.121)^{* * *}$ & $(68.3470)^{* * *}$ \\
\hline
\end{tabular}

(d) Estimation of dependence parameters

\begin{tabular}{|c|c|c|c|c|}
\hline \multirow{2}{*}{ Parameter } & \multicolumn{2}{|c|}{ Case 1 (all kinds of debt) } & \multicolumn{2}{|c|}{ Case 2 (housing/land debt) } \\
\hline & Frank-Joe & Dynamic Frank-Joe & R-Joe90-Joe & Dynamic R-Joe90-Joe \\
\hline \multirow{2}{*}{$\delta^{0}$} & \multirow{2}{*}{--} & 0.2384 & \multirow{2}{*}{---} & 7.9160 \\
\hline & & $(0.392)$ & & $(87.687)^{* * *}$ \\
\hline \multirow{2}{*}{$\varphi^{0}$} & \multirow{2}{*}{--} & $-0.2164^{* * *}$ & \multirow{2}{*}{---} & -0.7761 \\
\hline & & $(-3.542)$ & & $(-60.734)^{* * *}$ \\
\hline \multirow{2}{*}{$\theta^{0}$} & -2.265 & \multirow{2}{*}{-.- } & -1.99 & -.. \\
\hline & $(-24.838)^{* * *}$ & & $(-22.146)^{* * *}$ & \\
\hline \multirow{2}{*}{$\delta^{1}$} & \multirow{2}{*}{---} & 3.412 & \multirow{2}{*}{---} & -3.1370 \\
\hline & & $(1.789)^{*}$ & & $(-3.692)^{* * *}$ \\
\hline \multirow{2}{*}{$\varphi^{1}$} & \multirow{2}{*}{--} & 0.3242 & \multirow{2}{*}{--} & 0.2278 \\
\hline & & $(-1.701)^{*}$ & & $(2.765)^{* * *}$ \\
\hline \multirow{2}{*}{$\theta^{1}$} & 2.123 & \multirow{2}{*}{--} & 1.467 & \multirow{2}{*}{--- } \\
\hline & $(61.076)^{* * *}$ & & $(55.174)^{* * *}$ & \\
\hline $\log L$ & 67190.74 & 68144.1 & 74992.16 & 75081.88 \\
\hline AIC & -132169.0 & -136230.2 & -149930.3 & -150105.8 \\
\hline
\end{tabular}

Note. “***” denotes significance at $1 \%$ level. Source. Computation.

TABLE 4: Estimates of treatment effects of consumption.

\begin{tabular}{|c|c|c|c|c|c|c|}
\hline \multirow{2}{*}{ Copulas } & \multicolumn{3}{|c|}{ First case } & \multicolumn{3}{|c|}{ Second case } \\
\hline & I-I & $\mathrm{G}-\mathrm{G}$ & D-F-J & I-I & $\mathrm{G}-\mathrm{G}$ & D-RJ-J \\
\hline ATE of bootstrap & -838.72 & -893.27 & -952.82 & -17969.03 & -17657.06 & -17778.58 \\
\hline Standard deviation & 95.68 & 97.60 & 119.61 & 6208.20 & 6660.44 & 6158.43 \\
\hline \multicolumn{7}{|l|}{$95 \% \mathrm{CI}$} \\
\hline Lower & -1048.85 & -1113.9 & -1235.01 & -31676.20 & -32769.72 & -31891.25 \\
\hline Upper & -679.55 & -729.11 & -754.16 & -7661.82 & -6709.04 & -7620.15 \\
\hline TT of bootstrap & 1732.74 & 928.95 & -4935.51 & 4349.06 & 4385.26 & -8134.32 \\
\hline Standard deviation & 75.94 & 53.67 & 56.57 & 157.55 & 139.63 & 353.97 \\
\hline \multicolumn{7}{|l|}{$95 \%$ CI } \\
\hline Lower & 1568.31 & 811.36 & -4827.68 & 4032.47 & 4146.40 & -8835.55 \\
\hline Upper & 1865.79 & 1013.42 & -5041.70 & 4663.36 & 4681.45 & -7457.26 \\
\hline
\end{tabular}

do not have much difference between the static copula-based models and the dynamic copula-based models. Table 3(d) displays the estimated results of the dependence parameters for the two cases. First, the values of AIC in the bottom of Table 3 completely verify that the dynamic copula-based models are much better than the static copula-based models. Second, the coefficients of $\theta_{0}$ and $\theta_{1}$ for both the cases are significant and are equal to -2.265 and 2.123 in the first case, and -1.99 and 1.467 in the second case, respectively. This implies that the dependence between $\varepsilon$ and $\eta$ is a negative correlation, while $\varepsilon$ and $\xi$ are positively related. The negative dependency for the two cases indicates that a household that has a higher inclination to have debt or housing debt would consume more than an observationally equivalent "random" household if both these households do not have debt or housing debt. In other words, a household that makes the 

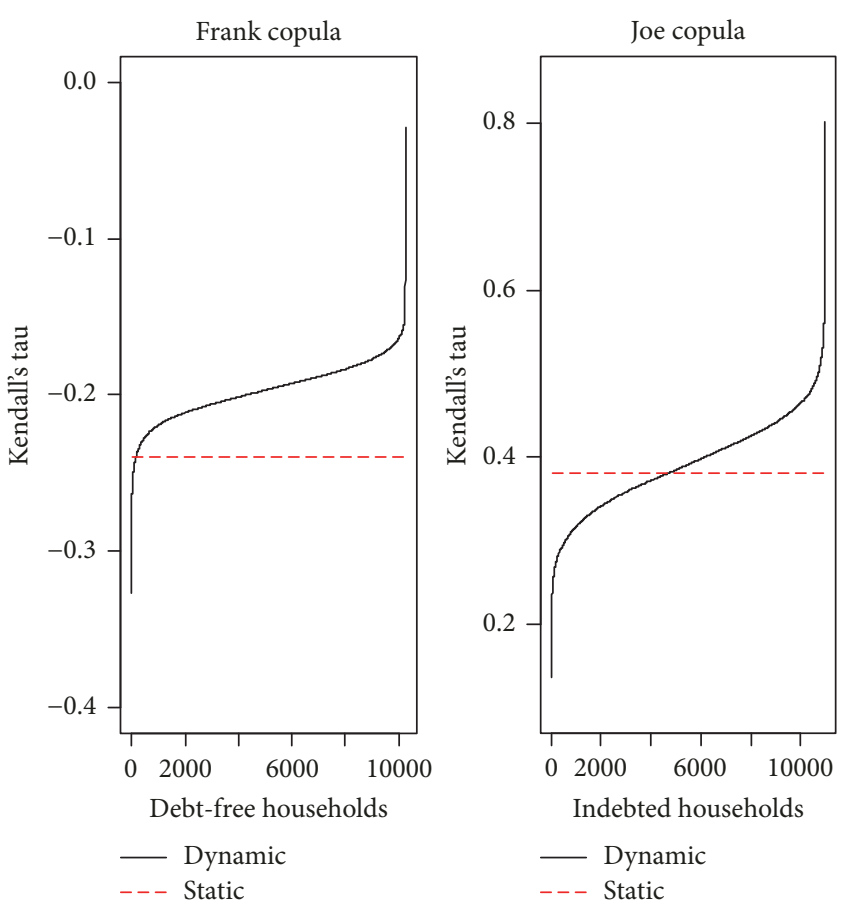

FIgURE 4: The dependence estimates (Kendall's tau) for the first case.

choice not to take loans is likely to consume less than a random household among debt-free households. While the positive dependency between $\varepsilon$ and $\xi$ implies that a household that has a higher probability to obtain bank loans is likely to consume less than a random household in indebted households. Equivalently, if an indebted household decides not to take loans, that household would consume much more than a random household in indebted households. Also, we find that the estimated $\alpha_{0}$ is highly statistically significant and negative for both cases, which means that when the household income is higher, the negative dependence between $\varepsilon$ and $\eta$ is bigger. We can believe that for households without debt, and for those that have high income and high consumption, there is a better probability of taking loans. In addition, the estimated $\alpha_{1}$ is highly statistically significant and positive, which indicates that where there is high income and high consumption, the probability of being converted into debtfree households is bigger in indebted households. Finally, Figures 4 and 5 describe the static and dynamic Kendall's tau for the two cases. They looked more natural, as expected, because they always had a negative or a positive correlation and did not hit the upper bound or the lower bound.

5.2. Estimation Results for Sample Selection Equations. Table 3(a) reports the estimated results of sample selection equations. For the first case, all the parameter estimates are statically significant at $1 \%$ level. The estimated parameters of the asset, expenditure, and number of children are positive, which implies that households with much asset or much expenditure or more children prefer to take loans. Perhaps, these households have concrete reasons to need the money. The parameter estimates of the age of the household head
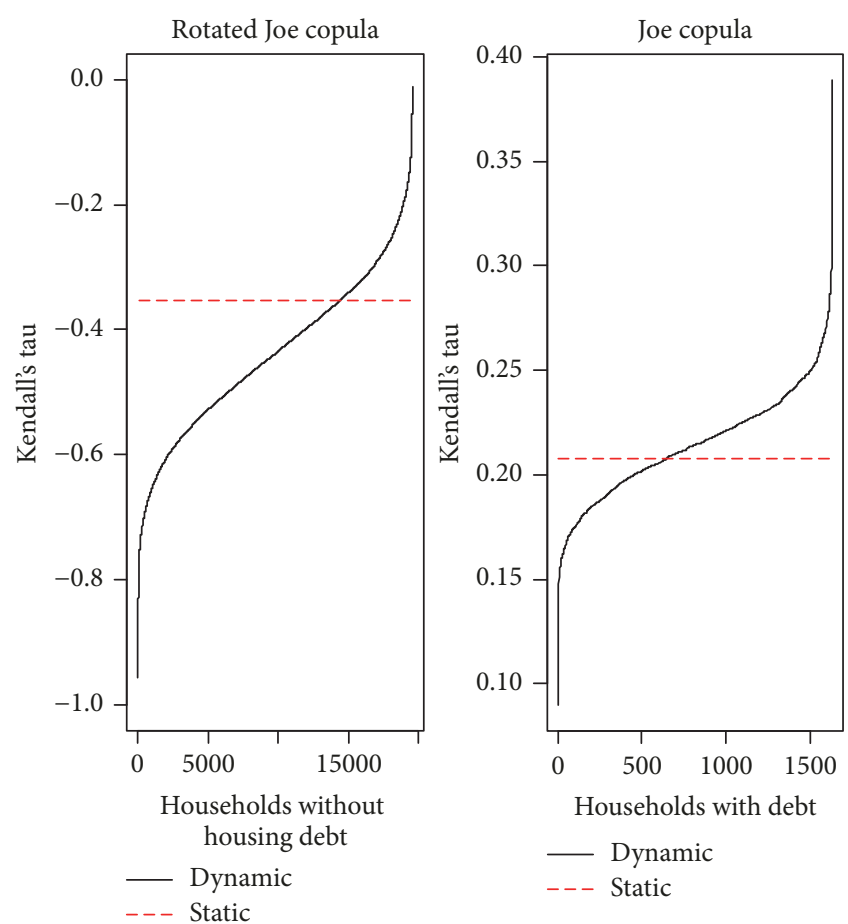

Figure 5: The dependence estimates (Kendall's tau) for the second case.

and the household income are negative, which indicates that households with elderly household heads or high incomes are not likely to take loans. For the second case, the coefficients of the asset and the expenditure are positive as well, while the coefficient of income is statistically significant and positive, which is opposite to that of the first case. This may be because households with high income can apply for housing or land debt. The parameter of the number of children is insignificant, which illustrates that the number of children does not have an effect on the choice of the housing debt. Upon comparing the second case with the first case, it can be observed that the parameter estimates of the asset and the income in the second case are greater than those in the first case. This implies that household asset and household income, as expected, have a pivotal effect on making decisions regarding housing debt.

5.3. Estimation Results for Consumption Equations. Table 3(b) reports the estimate results of consumption behavior in debt-free households and households without housing debt. As expected, the effects of the reciprocal of the household disposal income, the number of members, and the number of workers having stable jobs with steady income are statistically significant and positive. It is obvious that Table 3(c) shows results similar to those of Table 3(b). While comparing the intercepts of Table 3(b) with Table 3(c), we find that the intercepts of Table 3(b) are greater than the intercepts of Table 3(c). This implies that the household disposal income of debt-free households has a higher effect on household consumption than the household disposal income of indebted households. As for the second case, the household disposal income has 
effects similar to household income. The parameter estimate of the debt-asset ratio in the first case is negative and statistically significant, while it is positive in the second case. It is probably determined by the types of loan. For example, an excessive loan for education or consumer goods means much lower household income, and it causes a reduction in the household consumption. At the same time, a high debt-asset ratio with regard to housing debt indicates a substantially high household income which may increase the household consumption.

5.4. Treatment Effects. It is apparent that there are statistically significant indebted self-selection effects, which means that the choice of the household debt affects the household consumption. To measure the magnitude of the self-selection effects, we combine the treatment effect and the bootstrap method in this study. The ATE is estimated as follows:

$$
\mathrm{ATE}=\frac{1}{M} \sum_{j=1}^{M} \frac{1}{N} \sum_{i=1}^{N} \text { income }_{i j} \times\left(\widehat{\gamma}^{\prime} x_{1 i j}-\widehat{\alpha}^{\prime} x_{0 i j}\right),
$$

where $M$ is the number of bootstrap draws and $N$ is the sample size. $\widehat{\gamma}^{\prime}$ and $\widehat{\alpha}^{\prime}$ are from the estimates of the copulabased models. Let $M$, in this study, be a large number, 1000 . Following [8], the ATT can be estimated by

$$
\mathrm{ATT}=\frac{1}{M} \sum_{j=1}^{M} \frac{1}{N_{1}} \sum_{i=1}^{N} y_{i j} \times \text { income }_{i j} \times\left(\widehat{b}_{i j}^{(1)}-\widehat{b}_{i j}^{(0)}\right),
$$

where $N_{1}$ is the number of households with debt or housing debt and $\widehat{b}_{i j}^{(0)}$ and $\widehat{b}_{i j}^{(1)}$ are given as follows:

$$
\begin{aligned}
& \widehat{b}_{i j}^{(0)}=E\left(r_{0 i j} \mid y_{i j}^{*}>0\right)=\frac{1}{\widehat{\sigma}_{\eta}}\left\{1-F_{\varepsilon}\left(-\widehat{\beta}^{\prime} z_{i j}\right)\right\}^{-1} \\
& \times \int_{r_{0 i j}} r_{0 i j} \times\left(1-\frac{\partial}{\partial v_{i j}^{0}} C_{0}\left(u_{i j}^{0}, v_{i j}^{0} ; \widehat{\theta}_{i j}^{0}\right)\right) \\
& \quad \times f_{\eta}\left(\frac{r_{0 i j}-\widehat{\alpha}^{\prime} x_{i j}}{\widehat{\sigma}_{\eta}}\right) d r_{0 i j}, \\
& \widehat{b}_{i j}^{(1)}=E\left(r_{1 i j} \mid y_{i j}^{*}>0\right)=\frac{1}{\widehat{\sigma}_{\xi}}\left\{1-F_{\varepsilon}\left(-\widehat{\beta}^{\prime} z_{i j}\right)\right\}^{-1} \\
& \quad \times \int_{r_{1 i j}} r_{1 i j} \times\left(1-\frac{\partial}{\partial v_{i j}^{1}} C_{1}\left(u_{i j}^{1}, v_{i j}^{1} ; \widehat{\theta}_{i j}^{1}\right)\right) \\
& \quad \times f_{\eta}\left(\frac{r_{1 i j}-\widehat{\gamma}^{\prime} x_{1 i j}}{\widehat{\sigma}_{\xi}}\right) d r_{0 i j} .
\end{aligned}
$$

It is noticeable that $\widehat{b}_{i j}^{(0)}$ and $\widehat{b}_{i j}^{(1)}$ do not have a closed form. Thus, numerical integration by Simpson's rule is used to compute $\widehat{b}_{i j}^{(0)}$ and $\widehat{b}_{i j}^{(1)}$.

In this study, we calculate the point estimates of the treatment effects, the standard deviations, and the lower bound and the upper bound at $95 \%$ confidence interval. The results are presented in Table 4 for the independence-independence (I-I) copula-based models, Gaussian and Gaussian (G-G) copula-based models, and the two dynamic copula-based models corresponding to the dynamic Frank-Joe (D-F-J) copula-based model for case 1 and the dynamic rotated Joe-Joe (D-RJ-J) copula-based model for case 2. It is not surprising that most of the treatment effects are negative values as expected. First, let us focus on ATE. In the first case, the best-fitting D-F-J model indicates that a randomly picked household will reduce household consumption by 952.82 Baht per month if it is a household with debt relative to a debt-free household. At the same time, a randomly picked household will reduce household consumption by 17,778.58 Baht per month if it is a household with housing debt relative to a household without housing debt, according to the D-RJ-J model. It is thus clear that household housing debt has a much greater impact on household consumption than other debts. Second, the estimates of TT indicate that if a randomly picked household with debt were to be a debtfree household, the household consumption would have to increase by about $4,935.51$ Baht per month. If a randomly picked household with housing debt were to be a household without housing debt, the household consumption would have to increase by about $8,134.32$ Baht per month. Third, the I-I model ignores the sample selection effect, while the $\mathrm{G}-\mathrm{G}$ model is confined to bivariate normal assumption and linear correlation. This causes the I-I and the G-G models to underestimate the ATE and the TT relative to the best models.

\section{Conclusions}

The classical sample selection or endogenous switching model is restricted to a bivariate normal distribution on the error terms. Using bivariate normal distribution means there only exist linear and symmetric correlation between the error terms. These may have an impact on the sample selection effects. This study relaxed this assumption by using copula functions, and the dynamic copula was first proposed to be combined with the endogenous switching model. The dynamic copula is favorable for understanding the proper sense of the dependence structure between error terms. Moreover, the dynamic copula-based model is estimated by full information maximum likelihood method and does not entail any kind of numerical integration or simulation machinery. Thus, it is simple to apply to economic problems and will draw the attention of researchers.

This paper applied the copula-based endogenous switching approaches to model household debt choice and household consumption behavior using the data of 21,214 households in Thailand. The main results can be listed as follows: first and foremost, the dynamic copula-based models, the D-F-J copula-based model and the D-RJ-J copula-based model, have much better performance than the static copulabased models and the G-G copula-based models. On the one hand, this implies that the static dependence between error terms cannot accurately reflect self-selection effects. On the other hand, the assumption of bivariate normal distribution also affects self-selection effects. Second, we found that there exists negative dependence between debt-free 
household consumption and household debt choice, while it is positive dependence that exists between indebted household consumption and household debt choice. The negative dependence indicates that a household that makes the choice of not taking loans is likely to consume less than a random household in debt-free households. At the same time, the positive dependency implies that a household that has a higher probability to obtain bank loans is likely to consume less than a random household in indebted households. Also, the dynamic dependence means that if there is high income and high consumption, the probability of being converted into debt-free households is bigger in indebted households. Third, the estimates of ATE and TT of the dynamic copulabased models are very different from the estimates of the G-G copula-based models. The results showed that the classical G-G copula-based models underestimate the treatment effects. Moreover, it was observed that household housing debt has a much greater impact on household consumption than other debts, upon comparing the two cases. Last but not least, the study indicated that use of a traditional normal bivariate distribution or static copula function to characterize the relationship as regards errors between household debt choice and household consumption can lead to very misleading implications about treatment effects.

\section{Conflicts of Interest}

The authors declare that they have no conflicts of interest.

\section{Acknowledgments}

The authors are very grateful to Professor Vladik Kreinovich for his comments. The authors wish to thank the Puey Ungphakorn Centre of Excellence in Econometrics and the Bank of Thailand Scholarship for their financial support.

\section{References}

[1] K. Ogawa and J. Wan, "Household debt and consumption: A quantitative analysis based on household micro data for Japan," Journal of Housing Economics, vol. 16, no. 2, pp. 127-142, 2007.

[2] T. Ekici and L. Dunn, "Credit card debt and consumption: Evidence from household-level data," Applied Economics, vol. 42, no. 4, pp. 455-462, 2010.

[3] C. Meniago, J. Mukuddem-Petersen, M. A. Petersen, and I. P. Mongale, "What causes household debt to increase in South Africa?” Economic Modelling, vol. 33, pp. 482-492, 2013.

[4] S. Ni and Y. Seol, "New evidence on excess sensitivity of household consumption," Journal of Monetary Economics, vol. 63, pp. 80-94, 2014.

[5] M. Kukk, "How did household indebtness hamper consumption during the recession? Evidence from micro data," Journal of Comparative Economics, vol. 44, no. 3, pp. 764-786, 2016.

[6] S. R. Baker, "Debt and the response to household income shocks: Validation and application of linked financial account data," Journal of Political Economy, (forthcoming), 2017.

[7] M. D. Smith, "Using copulas to model endogenous switchings with an application to child labour," Economic Record, vol. 81, no. 1, pp. S47-S57, 2005.
[8] C. R. Bhat and N. Eluru, "A copula-based approach to accommodate residential self-selection effects in travel behavior modeling," Transportation Research Part B: Methodological, vol. 43, no. 7, pp. 749-765, 2009.

[9] B. Eberth and M. D. Smith, "Modelling the participation decision and duration of sporting activity in Scotland," Economic Modelling, vol. 27, no. 4, pp. 822-834, 2010.

[10] A. Wichian and S. Sriboonchitta, "Econometric analysis of private and public wage determination for older workers using a copula and switching regression," Thai Journal of Mathematics, pp. 111-128, 2014.

[11] J. Heckman, J. L. Tobias, and E. J. Vytlacil, "Four parameters of interest in the evaluation of social programs," Southern Economic Journal, vol. 68, no. 2, pp. 210-223, 2001.

[12] R. B. Nelsen, An Introduction to Copulas, Springer, New York, NY, USA, 2006.

[13] P. K. Trivedi and D. M. Zimmer, "Copula modeling: An introduction for practitioners," Foundations and Trends in Econometrics, vol. 1, no. 1, pp. 1-111, 2005.

[14] A. Wiboonpongse, J. Liu, S. Sriboonchitta, and T. Denoeux, "Modeling dependence between error components of the stochastic frontier model using copula: application to intercrop coffee production in northern Thailand," International Journal of Approximate Reasoning, vol. 65, pp. 34-44, 2015.

[15] S. Sriboonchitta, J. Liu, A. Wiboonpongse, and T. Denoeux, "A double-copula stochastic frontier model with dependent error components and correction for sample selection," International Journal of Approximate Reasoning, vol. 80, pp. 174-184, 2017.

[16] J. Du, H. Li, and Y. He, "The method of solving structural reliability with multiparameter correlation problem," Mathematical Problems in Engineering, vol. 2017, Article ID 6976301, 12 pages, 2017.

[17] P. Kumar, "Probability distributions and estimation of AliMikhail-Haq copula," Applied Mathematical Sciences, vol. 4, no. 13-16, pp. 657-666, 2010.

[18] M. D. Smith, "Stochastic frontier models with dependent error components," Journal of Econometrics, vol. 11, no. 1, pp. 172-192, 2008. 


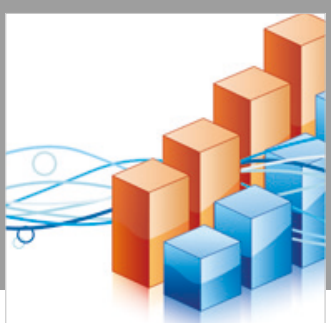

Advances in

Operations Research

\section{-n-m}
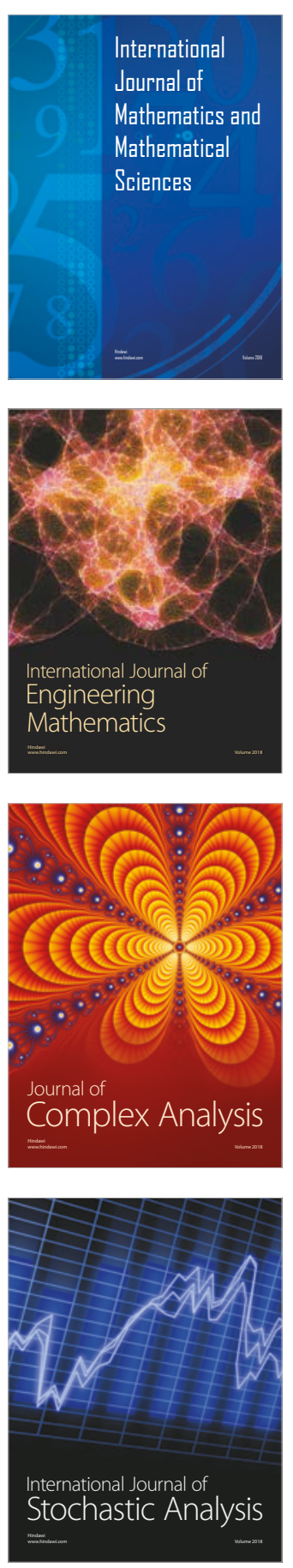
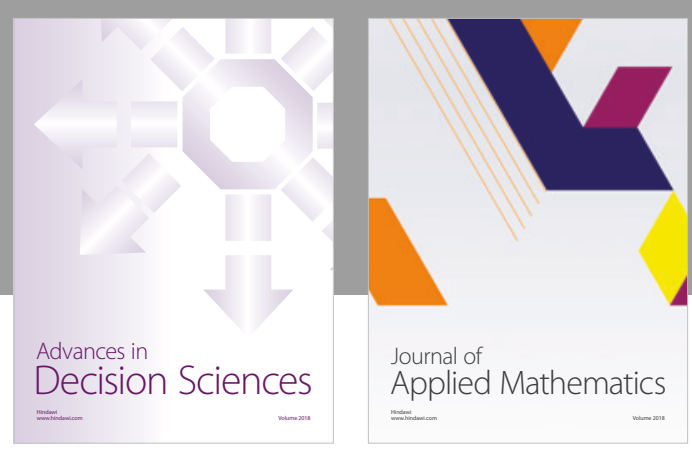

Journal of

Applied Mathematics
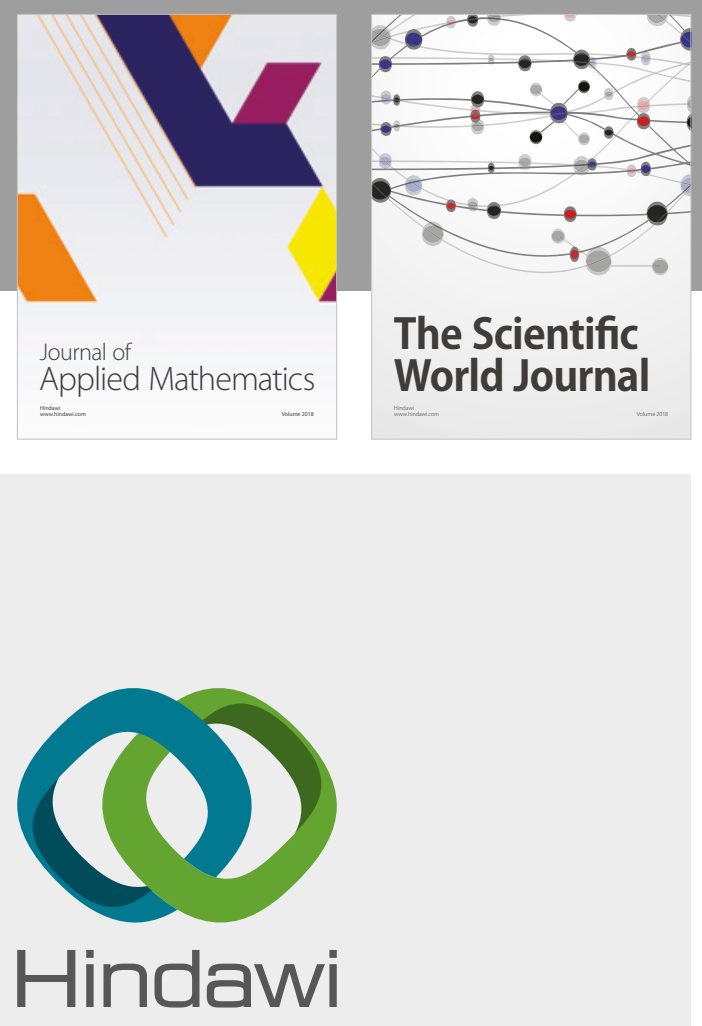

Submit your manuscripts at

www.hindawi.com

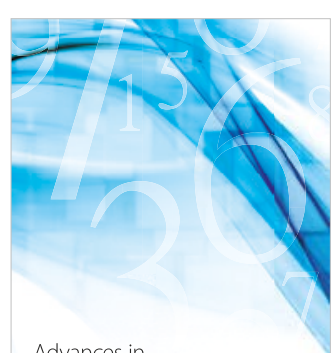

Advances in
Numerical Analysis
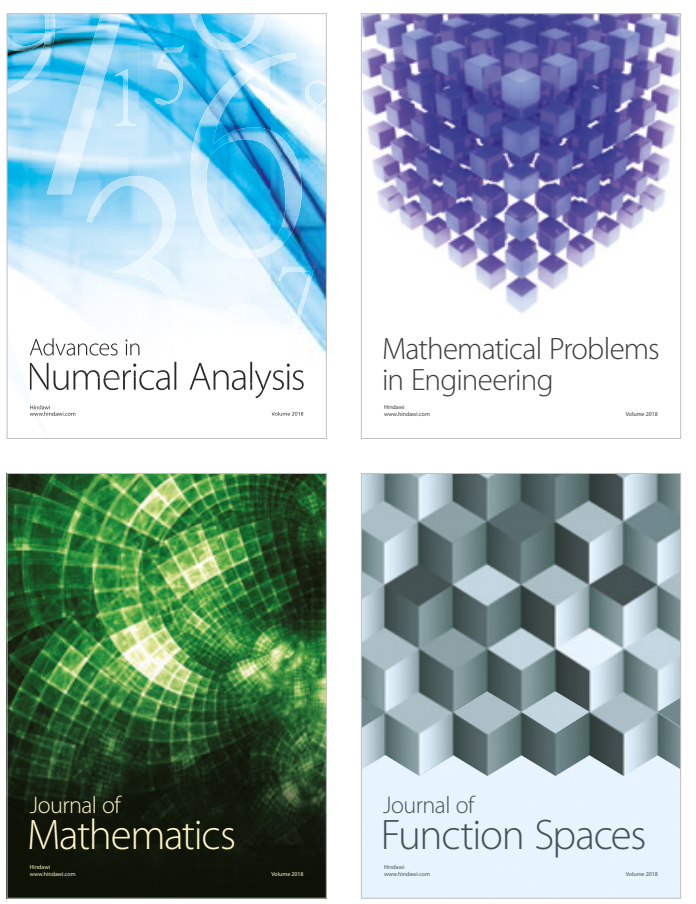

Mathematical Problems in Engineering

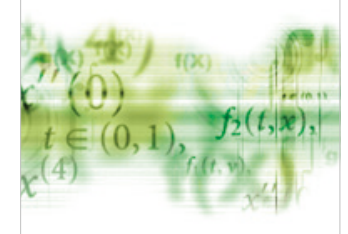

International Journal of

Differential Equations

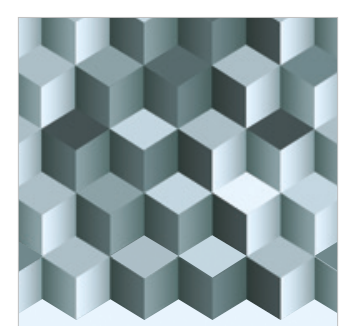

Journal of

Function Spaces

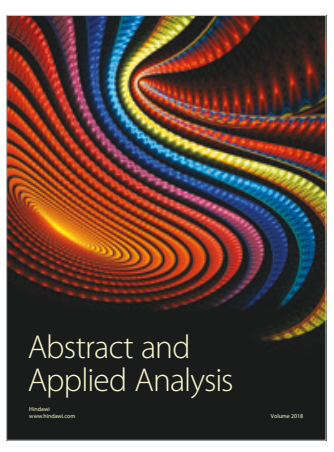

The Scientific

World Journal

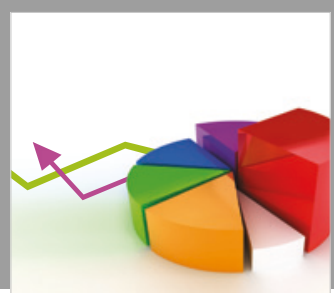

Journal of

Probability and Statistics
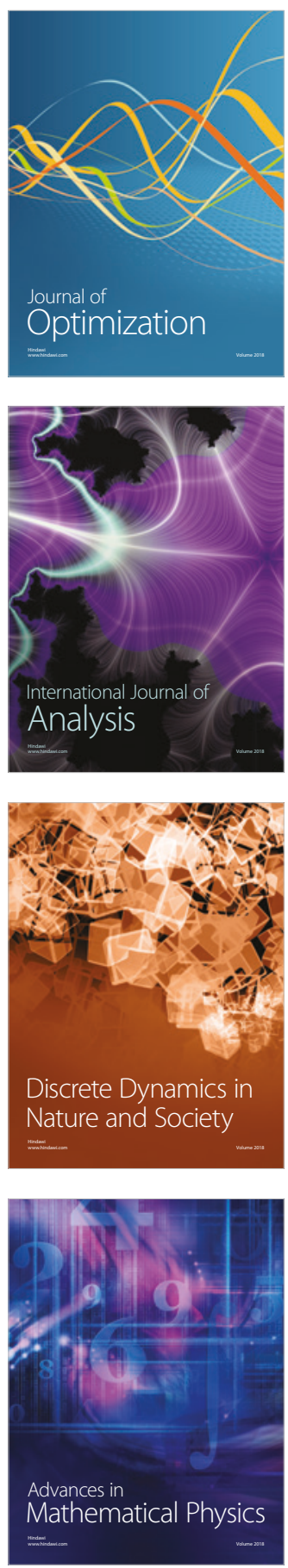